\title{
Developing a policy for paediatric biobanks: principles for good practice
}

\author{
Kristien Hens ${ }^{\star, 1}$, Carla E Van El ${ }^{2}$, Pascal Borry ${ }^{3}$, Anne Cambon-Thomsen ${ }^{4,5}$, Martina C Cornel ${ }^{2}$, \\ Francesca Forzano ${ }^{6}$, Anneke Lucassen ${ }^{7},{\text { Christine } \text { Patch }^{8} \text {, Lisbeth Tranebjaerg }}^{9}$, Eric Vermeulen ${ }^{2}$, Elena Salvaterra ${ }^{10}$, \\ Aad Tibben ${ }^{11,12}$ and Kris Dierickx ${ }^{3}$ on behalf of the PPPC of the European Society of Human Genetics ${ }^{13}$
}

The participation of minors in biobank research can offer great benefits for science and health care. However, as minors are a vulnerable population they are also in need of adequate protective measures when they are enrolled in research. Research using biobanked biological samples from children poses additional ethical issues to those raised by research using adult biobanks. For example, small children have only limited capacity, if any, to understand the meaning and implications of the research and to give a documented agreement to it. Older minors are gradually acquiring this capacity. We describe principles for good practice related to the inclusion of minors in biobank research, focusing on issues related to benefits and subsidiarity, consent, proportionality and return of results. Some of these issues are currently heavily debated, and we conclude by providing principles for good practice for policy makers of biobanks, researchers and anyone involved in dealing with stored tissue samples from children. Actual implementation of the principles will vary according to different jurisdictions. European Journal of Human Genetics (2013) 21, 2-7; doi:10.1038/ejhg.2012.99; published online 20 June 2012

Genetic and genomic research has made tremendous advances during the last decade. Its focus is the discovery of the functioning of genes in relation to health and disease. Effectively performing such research requires the study of large populations. Human biological material, such as blood and other tissue, genetic material in the form of DNA or RNA and baseline medical data from the donor, are important prerequisites. Such collections are often referred to as biobanks, although opinions differ on the precise definition. ${ }^{1-4}$ In this text we use the term 'biobank' as laid down by the P3G: An organised collection of human biological material and associated information stored for one or more research purposes (http://www. p3gobservatory.org/lexicon/list.htm).

This document is building on earlier work of the first and last author, analysing the opinions of stakeholders and analysing ethical principles. ${ }^{5-10}$ The current document and the principles for good practice have been drafted in collaboration with the Public and Professional Policy Committee of European Society of Human Genetics (ESHG). They have been posted on the ESHG website from 12 July 2011 to 31 August 2011 and ESHG members and several experts have been asked for comments. The final version of the document and the principles for good practice have been approved by the ESHG Board on 09 March 2012.

\section{Biobanks}

Collections of human biological materials have different origins and exist in different forms. ${ }^{11}$ Some are created to study a particular condition and contain samples from patients with that condition.
Others contain materials originally gathered for diagnostic purposes which are then partly secondarily used for non-therapeutic basic or translational research. For example, collections of material in the genetic centres of regional services or university hospitals contain material ascertained for diagnosis or management, but the 'left-over' samples could form a valuable resource for research into specific conditions.

Population or cohort studies often also have an associated biobank. In such studies phenotypic information is collected from a cohort or specific population and links with genetic variants are investigated. Longitudinal in nature, they create a resource for future unspecified research. Existing collections also form a good resource for genetic epidemiological and other research.

Many biobanks contain samples and information from competent adults, which enables the contributors to provide individual informed signed consent. The ethical issues related to the use of stored tissues samples for genetic research have been amply discussed in the literature, and involve the need for consent, the scope of consent, the need for privacy protection, the feedback of individual results and issues related to commercialisation of findings. In the past, complete anonymization of samples, making it impossible to trace back the identity of the original donor of the sample, has been recommended to avoid problems related to certain of these issues. As anonymization would avoid privacy breaches, it was often suggested as a way to allow reuse of existing collections, where donors were hard to trace. Today, with the advent of whole-genome sequencing, some have argued that complete anonymization becomes impossible. Also, there are certain

${ }^{1}$ Health, Ethics and Society, Maastricht University, Maastricht, The Netherlands; ${ }^{2}$ Clinical Genetics/EMGO Institute for Health and Care Research, VU University Medical Centre, Amsterdam, The Netherlands; ${ }^{3}$ Centre for Biomedical Ethics and Law, Katholieke Universiteit Leuven, Leuven, Belgium; ${ }^{4}$ UMR 1027, Inserm, Toulouse, France; ${ }^{5}$ UMR 1027, Université de Toulouse 3, Paul Sabatier, Toulouse, France; ${ }^{6}$ Clinical Genetics Unit, Galliera Hospital, Genova, Italy; ${ }^{7}$ Wessex Clinical Genetics Service, Southampton University, Faculty of Medicine, Southampton, UK; ${ }^{8}$ Department of Clinical Genetics, NIHR Biomedical Research Centre, Guys and St Thomas' NHS Foundation Trust, Guys Hospital, London, UK; ${ }^{9}$ Department of Audiology, H:S Bispebjerg Hospital, Copenhagen NV, Denmark; ${ }^{10}$ Unit of Bioethics, Scientific Institute 'Medea', Bosisio Parini, Italy; ${ }^{11}$ Centre for Human and Clinical Genetics, Leiden University Medical Centre, Leiden, The Netherlands; ${ }^{12}$ Department of Clinical Genetics, Erasmus Medical Centre, Rotterdam, The Netherlands ${ }^{13}$ For a list of collaborators, see Appendix.

*Correspondence: Dr K Hens, Health, Ethics and Society, Maastricht University, PO Box 616, 6200 Maastricht, The Netherlands; E-mail: k.hens@maastrichtuniversity.nl

Received 30 March 2012; revised 20 April 2012; accepted 26 April 2012; published online 20 June 2012 
drawbacks: it does not allow recontacting people for follow-up research or if individual results are shared. Therefore, the use of coded samples, where individual researchers do not have access to the identity of the donor, is now more common.

\section{Children in research}

In the last century, the status of children has changed significantly and a number of rights unique to children have come to be recognised. This is defined in the 1989 Convention on the Rights of the Child, ${ }^{12}$ which is an internationally legally binding document containing principles founded on respect for the dignity and worth of each child, regardless of race, colour, gender, language, religion, opinions, origins, wealth, birth status or ability. An aim of the Convention is to protect children, to help secure their basic needs and to enhance the possibility of reaching their best potential.

The recognition of the rights of children has changed in medical research as well, following several high profile research studies exhibiting malpractice, and little respect for children's rights and concerns. ${ }^{13}$ As a result of these, children are now considered to be in need of extra protection due to their vulnerability. In this document, we shall use the term 'minor' to denote individuals from birth till they reach the age of majority. We are aware that the legal definition of 'minor' varies by country.

Genetic or genomic research on archived samples from children is useful. Much genetic research combines the study of DNA with that of medical and lifestyle data, and data starting from childhood enables long-term research. Many common conditions such as allergies, asthma, food intolerance, diabetes and obesity have a multifactorial aetiology and can often be attributed to a combination of genetic and environmental or lifestyle factors. Also the rapidly expanding field of epigenetics explores the influence of in utero exposure, for example, on gene expression.

There are different forms of paediatric biobanks. Large cohort studies follow children from birth onwards into adulthood, collecting phenotypic and lifestyle data together with genetic information. Other biobanks concentrate on conditions that occur during prenatal life or childhood, such as congenital defects or childhood cancer, and use material from children who develop these conditions. Existing collections, such as newborn blood spot cards, may also form a useful resource for genetic epidemiological research. ${ }^{14,15}$

\section{Research on children: principles and ethics of paediatric clinical trials}

Current principles regarding the participation of minors in research are in many cases laid down in the context of clinical trials. Here, the principle of minimal risk is often quoted as defining a standard by which one can decide whether some proposed non-therapeutic research can be performed with children. ${ }^{16,17}$ Hence, minimal risk is understood as a risk that is not higher than what a child would encounter in everyday life. Moreover, the direct benefits should counterbalance the risk of a procedure. ${ }^{18}$ For example, European normative frameworks for clinical trials (Article 4, Directive 2001/20 EC of the European parliament and of the Council of 4 April 2001) hold that research on minors should be performed out of necessity, either because there might be some direct benefit to the participant, or because the research could benefit children with the same condition. ${ }^{17}$ The risks also need to be proportional to the potential net benefits for the child participating in the clinical trial. Another concept quoted in the context of clinical trials with minors is that of subsidiarity: such research should only be done if it cannot be done on adults.

\section{Research on biological samples from children}

Genetic or genomic research using biobanked biological samples from children poses additional ethical issues to those raised by using adult biobanks. For example, small children have only limited capacity, if any, to understand the meaning and implications of the research and to give a documented agreement to it. Older minors are gradually acquiring this capacity. Also, the ethical questions are different from those raised by paediatric clinical trials. Many of the concepts discussed in the literature on paediatric biobanks, such as minimal risk and benefit, are deduced from the clinical trials context where the balancing between risks and benefits is more straightforward, as such research often may have direct benefit to the participant. In nontherapeutic biobank research, the question of benefit is more complex, as in many cases there will not be direct benefit to the participant, only potential benefits to future patients. Hence, the amount of risk a research subject is allowed to be subjected to in this type of research cannot be automatically balanced against the potential benefit he or she gains from the research. Also, biobanks facilitate research on stored biological samples rather than on the child him- or herself, making the procedures less physically risky.

The participation of minors in biobank research can offer great benefits for science. However, as minors are a vulnerable population they are also in need of adequate protective measures when they are enroled in research. In a recent study, researchers have recognised the need for adequate policies regarding paediatric biobanks. ${ }^{19}$ In this document we describe the main issues related to the inclusion of minors in biobank research, and provide principles for good practice. It is addressed to policy makers of biobanks, researchers and anyone involved in dealing with stored tissue samples from children. Where applicable, we make a distinction between different types of biobanks. The issues arising from clinical or disease-oriented collections may be different from those arising from population-based ones. Clinical or disease-oriented collections may be relatively small in scale, and patient organisations often have a significant role. ${ }^{20}$ The aims of participants and researchers in disease-oriented collections are more congruent than in population-based biobanks. Also, the ethical issues arising from the use of samples gathered in a diagnostic setting may be different from those arising from the use of samples gathered primarily for research. For example, there is no need to perform extra venepunctures for research purposes only, and there is often more direct contact between researchers, who are sometimes also clinicians, and participants.

Actual implementation of the principles will vary according to different jurisdictions. For example, in some jurisdictions, written consent will be necessary for any genetic research on stored tissue samples, whereas in others it will be enough that participants are verbally notified. Also, samples may sometimes not be shared across borders, or may not be completely anonymised. In this document we focus on the issues related to benefits and subsidiarity, consent, proportionality and return of results. Hence, there are some elements we do not address in this document, such as the use of samples by private companies, patenting and the use of samples from deceased persons. A proportion of the minors donating biological samples for genetic research will never reach the age of majority or will never have legal competence due to their health status. In such cases, some of the issues described above will not apply or will require modification.

We shall for each issue describe the general principle, and then give examples of how these principles may be differently implemented in different types of biobanks. At the end of the document we have formulated recommendations. 


\section{BENEFITS AND SUBSIDIARITY \\ Principle}

The requirement of personal benefits, which states that research on minors can be done if it provides direct benefit to the minor, is derived from clinical trial ethics and is difficult to transfer to biobanking. The probability of personal medical benefit to a minor is small in the case of research using human biological materials. The requirement of group benefit holds that research on children is permissible if results of the research may benefit other children with the same condition. Also the concept of group benefit has been discussed in the context of biobanking. Some have argued an actual cure or treatment cannot be immediately derived from genetic research. ${ }^{8}$ Others have argued, the possibility of accurate genetic diagnosis in the future may also be seen as a group benefit.

Some have argued that a minor also gains benefit from being altruistic while participating in medical research. ${ }^{21}$ So, even if a child does not benefit medically from contributing to research, such research is legitimate, both from a viewpoint of personal benefit as well as of group benefit. Indeed, a recent line of thought in medical research stresses the fact that research with and for children is legitimate, and a focus on the risks does not do justice to either the participating children or the children benefiting from the research. ${ }^{22}$

The concept of subsidiarity holds that research on minors should only be done if the results from research on adults are not transferable to children. However, this does not limit the research to the study of paediatric conditions or age-related phenome/genome alterations. Also late-onset diseases that may be caused by factors that occur during childhood may be studied, or studies of general genome variation characteristics that compare age groups in various populations/environmental conditions and give insights in gene/environment interactions may generate unique and useful knowledge of interest. In the case of scarce resources, biological samples from children could also be used if adult biological samples are unavailable.

\section{CONSENT}

\section{Necessity of consent}

Principle. A much discussed issue in the context of biobanks in general is that of consent. With paediatric biobanks, this question is even more complicated, as small children are typically not able to provide consent for themselves. ${ }^{23,24}$ Consent from a parent or a legal guardian is required for the child's biological sample to be stored and used in biobank research (On the P3G website, examples of consent forms can be found: http://www.p3gobservatory.org/lexicon/list.htm).

Application. When minors are enroled in primary research protocols, it is straightforward that parents are asked to consent to the participation of their children in such research, for example, in the case of longitudinal cohort studies. Parents can be asked to consent at the time of enrolment. However, in some jurisdictions, this requirement may be waved in certain low-risk research, such as research on anonymised samples, or research on left-over material. In such cases it may not always be possible or necessary to recontact parents. It may still be allowable to use such samples in research, provided there is true oversight and approval of an ethics committee, and specifically when samples are anonymised this may be the case.

\section{Scope of parental consent}

Principle. As minors grow towards maturity the relative importance of parental consent reduces. The processes of obtaining assent or consent from adolescents may vary per context and country. Young people reaching the legal age of majority should have the opportunity to renew or withdraw consent for storage and use of their samples and data from biobanks (Of course, the right to withdraw extends also after a person reaches the legal age of competence). Moreover, as small children's wishes cannot be trusted as an expression of their autonomy and as their preferences may change as they grow older, there is a risk that certain research would be contrary to their evolving wishes. This is especially the case when research on stored biological samples extends over time. In principle, minors have the right to receive age-appropriate information and agree or disagree (assent or dissent) about the destination of their samples. Even young children prefer to receive some information at their level of understanding. ${ }^{25,26}$ This right is limited by their ability to comprehend to what they are agreeing to. This comprehension gradually increases as they acquire more cognitive ability and more autonomy. Those monitoring biobanks should develop procedures that allow a child to assent, dissent and eventually consent or refuse as they mature.

Application. It is mandatory without any exceptions that at the majority age the participant in principle can reconsent or withdraw his/her consent. This may imply that young people should be recontacted when they reach the age of majority. If the specific type of biobank allows recontacting participants, they should consider making young adults on the verge of majority aware that their samples are being used in research and that it would be possible for them to withdraw their samples from further research. Depending on the setting, letters could be sent to participants when the age of legal majority approaches. Alternatively the research could be advertised on a dedicated official website with the possibility for participants to contact the biobank or their treating physician regarding the use of the samples. Or, at time of enrolment, parents could be asked to inform their children as they grow older and be reminded to do so when the age of legal majority approaches, if they have not done so already. Although information technology is already being used in certain cases for on line or at least electronic forms of informed consent (See for example http://www.ncbi.nlm.nih.gov/pubmed/16127857, ftp:// 128.95.1.178/tr/2000/12/UW-CSE-00-12-02.pdf, http://www.ukbiobank. ac.uk/wp-content/uploads/2011/06/Consent_form.pdf and http://www. ssi.dk/nyfoedte) in the web 2.0 era there would be many strategies available to recontact parents or children. ${ }^{27}$

Where there is frequent contact between participants and the research team, the maturity of minors and their capability to decide for themselves whether they want to continue participating or not can be assessed by the researchers, parents and minors together on a caseby-case basis. If there was a one-time donation of the sample with no further contact with the participant a fixed age threshold is most realistic.

However, recontacting minors may not be feasible in all cases, for example, because many people change addresses, or because anonymised samples are used in epidemiological research. Therefore, the duty to recontact could perhaps be done on a best effort basis. If recontacting a minor is not possible, an ethics committee should decide on the fate of the sample. Also, samples and information about the samples are potentially shared with researchers in other jurisdictions, making complete withdrawal of all information sometimes impossible. In any case, parents and children should be informed about the possible challenges of complete withdrawal at time of enrolment.

\section{Specific or broad consent}

Principle. Next to determining who should give consent, it is important to consider what content is necessary to ensure adequate 
consent. In debates about adult biobanks, authors have considered whether so called 'broad' consent-consent to future unspecified research is appropriate. ${ }^{28-30}$ Some have argued that as long as participants have the right to withdraw their samples and that there is clear research governance including ethical committee oversight and involvement of stakeholders such as patient organisations, broad consent is possible for adults. In the case of paediatric stored tissue samples this issue is further complicated by the fact that parents give consent for their children. Can parents be allowed to give broad consent for any future research on their children's samples until the age of majority? On the one hand, as we stated before, minors, as persons growing towards autonomy and acquiring their own values, should be given the opportunity to express their choices. On the other hand, it may also be administratively impractical to recontact minors and/or their parents for each change in the research protocol. Moreover, many participants would not want frequent recontact. People may have different attitudes towards different aims and kinds of science, however, there is much general support for research that would lead to treatment or better understanding of medical conditions. Less expressed support exists for fundamental research on genome structures and functions, maybe because the clinical benefit is more complicated to explain than the significance for medical conditions. However, fundamental research may eventually also result in knowledge advances that may allow medical progress without this being foreseen. It may be permissible to assume that such research is part of the original parental consent, although some disease categories may be more sensitive than others, such as psychiatric diseases.

Application. It is a good policy to make parents and their older children aware of the type of research done on their samples and give them the opportunity to withdraw their participation. This will be easier if the type of biobank entails frequent contact between participants and researchers. In such cases, participants and their parents may be notified personally of new research. In case of a single donation of a sample or of epidemiological research on anonymous samples, this is more difficult, if not impossible. Ethics committees should be consulted before the start of sampling for the biobank, but also when research changes considerably from the original description given before the consent. The committee may advice whether recontact is necessary. In any case, different media including websites should be used to ensure transparency of the research, especially for those cases where donors can no longer be tracked.

\section{Proportionality}

Principle. When medical research has the potential to treat certain diseases, researchers can appeal to the principle of solidarity to enrol participants. ${ }^{31,32}$ However, such an appeal is restricted when participants are minors, as they have a limited autonomy and understanding and are therefore vulnerable. Any research exposure should therefore involve only minimal risks. ${ }^{8,33}$ What does the term risk entail in the context of biobanks?

Genetic information may reveal information about the health status of the individual. Research that may discover this should therefore be performed with clear governance and data-protection procedures in place. Privacy risks should be addressed on two levels. First, society in general should operate in a framework of fair institutions and privacy laws. These frameworks need to be able to help facing concrete situations in the evolving technological world. The Data protection Directive (Directive 95/46/EC) that sets the legal requirements in this respect in all EU countries is currently under revision following a set of public consultations (http://ec.europa.eu/ justice/data-protection/index_en.htm). It has specific dispositions for research. Second, the governance of the biobank is important and should include appropriate data-protection policies. This is especially the case when samples are shared with researchers outside the biobank. For example, samples and data should be coded, so that the identity of the donor is not available to the researcher using the sample. Balancing the privacy of participants and research requirements is challenged by developments in science and technology. There again information technologies may help implementing appropriate procedures. ${ }^{34}$ Also, good governance assumes that citizens and patient organisations have been involved and consulted in the setup of the biobank. We assume that such baseline safeguards are already in place or are taken into consideration. ${ }^{8,31}$ We admit that the requirement of good governance is harder to control when samples are shared across national borders, an issue which may be further complicated in the case of paediatric biobanks, and which is still under discussion. ${ }^{35-38}$

Application. Empirical research has shown that respondents are most concerned about the burden of non-therapeutic medical research to children, especially the physical burden. ${ }^{7,39,40}$ Potential burdens depend on the biobank in question: it may be less relevant in research using collections that were gathered in a diagnostic or screening context and that do not require further contact between participants and researchers. However, if diagnostic or screening samples are used, it should be confirmed that enough material remains for follow-up of the original clinical purpose. If new samples are required the procedures should cause the least physical and psychological discomfort as possible. Also, non-physical burdens may occur in genetic research, such as burdens associated with the knowledge of certain genetic information.

\section{Feedback of results}

Principles. In biobanks, two types of results can be fed back. First, aggregate results of a study can be sent to participants or published on a website. Second, research may generate health information about specific participants. Such information may be the direct result of the research or may be generated as an incidental finding. We shall discuss them both as 'individual results' in this section. We shall not discuss here the feedback of results from direct observations, such as blood pressure, because it is not the focus of the paper.

Debates around the feedback of individual results in the case of adult biobanks ${ }^{41-47}$ distinguish three broad stances. (1) No individual results are fed back to participants, because this might generate anxiety while the results themselves may be insecure and preliminary or because could enhance the therapeutic misconception. Moreover, biobanks are also primary research tools and feeding back individual results implies that too many resources would have to be allocated to this feedback. (2) Participants are given a choice whether to receive individual results or not. In this case, the communication may differ according to the type of disease: early or late onset or whether the finding concerns carrier status. In some research settings, for example at $\mathrm{NIH}$, the primary researchers are recontacted on the recent/new results and are advised to contact the families. If the parents/patients do wish to receive a final report they are asked to give new samples (whenever possible) to test at a diagnostic laboratory or the results should be confirmed with an independent sample. (3) Results are fed back depending on their potential benefits: if a result has clinical relevance and may modify the course of management it is fed back. However, the complexity of interpretation and the difficulty of determining the scientific validity and clinical utility of the results 
should not be underestimated. ${ }^{48}$ Feedback discussions ${ }^{10}$ should debate both the right of participants to such information as well as any duty that a researcher might have to provide it, either to the parents or to the child's physician.

As children do not enrol themselves in the research, the question whether research findings are fed back needs addressing. As a principle, parents are supposed to consider the best interest of their child. Hence, they should not opt out of receiving information that is relevant to the health of their children, if they decide to enrol their children in non-therapeutic research. In this respect, the potential benefits for the child in the case of certain diseases should prevail over the right of the parent not to know. In the case of genetic research, this may refer to early-onset treatable or preventable disorders, in accordance with guidelines regarding genetic testing of children. ${ }^{49}$ Such discoveries at the present time are only applicable to genetic conditions such as familial adenomatous polyposis or hypertrophic cardiomyopathy, where preventive actions or actions for early detection can be taken during childhood. Revealing information about treatable or preventable conditions that are of adult onset should usually be postponed until the young person can decide for him or herself whether to receive such information. ${ }^{50}$ It is part of the right of the minor to an open future that he or she can decide whether or not certain genetic information is given to him or her. However, if the genetic information is relevant for future reproductive choices of the parents, one should find a way to inform them. Moreover, some have suggested that the scope of certain genetic tests for minors should be widened to include also severe, but nontreatable/preventable diseases, to avoid medical Odysseys. ${ }^{51}$ Changes in policies regarding paediatric genetic tests may affect the policy of the biobank regarding the feedback of individual results.

Within the scope of the researcher's duty, feedback of information about early-onset preventable or treatable conditions may be more advisable in the case of paediatric biobanks than in case of adult biobanks, because of the fact that children do not enrol themselves and are hence more vulnerable.

Application. The implementation of the duty to feedback early-onset preventable or treatable conditions will depend on the type of the biobank, and on the actual legal framework. It is dependent on the type of collection, the feasibility of providing genetic counselling and the possibility of checking the findings for clinical validity and utility. On the one hand, studies involving children often involve more direct contact between researchers and children and are done in a clinical setting. If studies are done in a clinical setting, it may be unethical not to inform the subject of results with actionable clinical implications. On the other hand, epidemiological research that puts no burden on children and implies no contact between the researcher and the child, or where it may be harder to validate the findings clinically may be exempted from this rule.

\section{CONCLUSIONS}

The inclusion of biological samples from minors in biobanks, and their subsequent research use, may contribute to the knowledge and treatment or prevention of many paediatric conditions. However, this inclusion also raises ethical questions, which are not analogous to those encountered in the use of tissue samples from adults or to the issues associated with clinical trials. These ethical issues also have policy implications. In this document we have laid down some issues that should be considered when starting up a paediatric biobank or when using existing collections of biological samples from children for research. Issues include the need for parental consent, the scope of parental consent and the duty to recontact young adults, and the right of a child to assent or dissent. They also include the requirement of minimal risk, be it physical, emotional or informational risk, and the requirement that research should benefit other children or should not be equally possible with adults. Also the question whether or not to return individual results deserves special considerations when participants are children. There may be more reason to return such results, especially when the condition found is preventable or treatable in the early years of life.

When developing a policy for paediatric biobanks, the type of biobank in question is also relevant. Different requirements should be taken into account when there is no frequent contact between participant and researcher, or when there is no possibility for genetic counselling. On the one hand, issues such as return of results or recontact are impossible when samples are completely anonymised which could be the case in large-scale epidemiological genetic research. On the other hand, withholding relevant medical information or not informing a child about research done on his or her DNA may be unacceptable when there are frequent contacts between researchers and participants or when the research is done in a clinical context.

\section{PRINCIPLES FOR GOOD PRACTICE}

1. Genetic research on stored biological samples from minors should only be done if the research questions cannot be answered by a study of adults (subsidiarity principle).

2. The collection and use of biological samples and data from minors should minimise physical and psychological burden.

3. The focus of who decides about the collection, storage and use of samples gradually shifts from the parents to the minor as he or she grows older and/or reaches the age of majority.

4. Minors should receive age-appropriate information about the collection, storage and use of their samples, and a minor's assent or dissent should be respected.

5. Minors should be given the opportunity to contact researchers and to withdraw their samples, if they so wish, when they are mature enough or when they reach adulthood.

6. A best effort should be made to communicate the progress of research. The purpose of ongoing research should be transparent, either through direct communication with the participants or through communication via for instance a website or newsletters.

7. Biobanks should have a policy about returning information about preventable or treatable conditions of early onset when participants are minors. Details of this should be included in the consent forms.

8. The right of parents to receive or not to receive genetic information about their children is limited. In the rare case that information about a preventable or treatable early-onset disease is found, they should be notified regardless of their wishes providing the findings are subject to assessment of clinical validity and utility.

\section{ACKNOWLEDGEMENTS}

K Hens was supported by FWO Flanders, project number G029107. A Cambon-Thomsen was supported for his work on biobanks by two FP7 EU projects: BioSHaRE-EU (GA no 261433) Biobank Standardisation and Harmonisation for Research Excellence in the European Union and EU FP7-212111 infrastructure project BBMRI (Pan-European Biobanking and Biomolecular Resources Research Infrastructure). 
1 Deschênes M, Glass KC, Cardinal G, Knoppers BM: Human genetic research, DNA banking and consent: a question of 'form'? Clin Genet 2001; 59: 221-239.

2 Elger BS, Caplan AL: Consent and anonymization in research involving biobanks: Differing terms and norms present serious barriers to an international framework. EMBO Rep 2006; 7: 661-666.

3 Godard B, Aymé S, Schmidtke J, Cassiman J-J: Data storage and DNA banking for biomedical research: informed consent, confidentiality, quality issues, ownership, return of benefits. A professional perspective. Eur J Hum Genet. 2003; 11(Suppl 2): S88-S122.

4 Rothstein MA: Expanding the ethical analysis of biobanks. J Law, Med Ethics 2005; 33: 89-101.

5 Hens K, Nys H, Cassiman JJ, Dierickx K: Genetic research on stored tissue samples from minors: a systematic review of the ethical literature. Am J Med Genet A 2009; 149A: 2346-2358.

6 Hens K, Nys H, Cassiman JJ, Dierickx K: Biological sample collections from minors for genetic research: a systematic review of guidelines and position papers. Eur J Hum Genet 2009. 17: 979-990.

7 Hens K, Nys H, Cassiman JJ, Dierickx K: The storage and use of biological tissue samples from minors for research: a Focus Group Study. Public Health Genomics 2011; 14: 68-76.

8 Hens K, Nys H, Cassiman JJ, Dierickx K: Risks, benefits, solidarity: a framework for the participation of children in genetic biobank research. J Pediatr 2011; 158: 842-848.

9 Hens K, Nys H, Cassiman JJ, Dierickx K: Children, biobanks and the scope of parental consent. Eur J Hum Genet 2011; 19: 735-739.

10 Hens K, Nys H, Cassiman JJ, Dierickx K: The return of individual research findings in paediatric genetic research. J Med Ethics 2011; 37: 179-183.

11 Cambon-Thomsen A: The social and ethical issues of post-genomic human biobanks. Nat Rev Genet 2004; 5: 866-873.

12 United Nations Convention on the Rights of the Child 1998

13 Lederer SE, Grodin MA: Historical overview: pediatric experimentation; in Grodin MA, Glantz LH (eds): Children As Research Subjects. Science, Ethics \& Law. New York and Oxford: Oxford University Press, 1994; pp 3-25.

14 Patel P, Mulla H, Tanna S, Pandya H: Facilitating pharmacokinetic studies in children: a new use of dried blood spots. Arch Dis Child 2010; 95: 484-487.

15 Klotz J, Bryant P, Wilcox HB, Dillon M, Wolf B, Fagliano J: Population-based retrieval of newborn dried blood spots for researching paediatric cancer susceptibility genes. Paediatr Perinat Epidemiol 2006; 20: 449-452.

16 Kodish E: Ethics and research with children: An introduction; in Kodish E (eds): Ethics and Research With Children. A Case-Based Approach. Oxford and New York: Oxford University Press, 2005; pp 3-25.

17 Pinxten W, Dierickx K, Nys H: Ethical principles and legal requirements for pediatric research in the EU: an analysis of the European normative and legal framework surrounding pediatric clinical trials. Eur J Pediatr 2009; 168: 1225-1234.

18 Bernard-Bonnin A-C: Les principes éthiques de la recherche biomédicale avec les enfants; in Delfosse M-L, Parizeau M-H, Amann J-P (eds): La Recherche Clinique Avec Les Enfants: à La Croisée De L' Éthique Et Du Droit Belgique, France, Québec. Louvain-la-Neuve: Anthemis, 2009; pp 415-424.

19 Salvaterra E, Giorda R, Bassi MT et al: Pediatric biobanking: a pilot qualitative survey of practices, rules, and researcher opinions in 10 European countries. Biopreserv Biobank 2011; 10: 29-36.

20 Wichmann HE, Kuhn KA, Waldenberger M et al: Comprehensive catalog of European biobanks. Nat Biotechnol 2011; 29: 795-797.

21 Gaylin W, Macklin R: Who Speaks for the Child? The Problems of Proxy Consent. New York: Plenum Press, 1982.

22 Klassen TP, Hartling L, Hamm M, van der Lee JH, Ursum J, Offringa M: StaR Child Health: an initiative for RCTs in children. Lancet 2009; 374: 1310-1312.

23 Shickle D: The consent problem within DNA biobanks. Stud Hist Philos Sci 2006; 37 : 503-519.

24 Holm S: Informed consent and the bio-banking of material from children. Genomics Soc Policy 2005; 1: 16-26.

25 McDonagh JE, Bateman B: 'Nothing about us without us': considerations for research involving young people. Arch Dis Child Educ Pract Ed 2011; 97: 55-60.

26 van der Pal S, Sozanska B, Madden D et al: Opinions of children about participation in medical genetic research. Public Health Genomics 2011; 14: 271-278.

27 Norgaard-Pedersen B, Hougaard DM: Storage policies and use of the Danish Newborn Screening Biobank. J Inherit Metab Dis 2007; 30: 530-536.

\section{APPENDIX}

Collaborators during the process of public and expert consultation Emmanuelle Rial-Sebbag and Velizata Anastasova: sent comments on behalf of the work package 'Ethics' of the FP7 EU project MeDALL (GA no 261357) Mechanisms of the Development of ALLergy.

People sending comments during the consultation phase were: Denise Avard, Kyle Brothers, Angus Clarke, Trevor Cole, Christine De Die, Constantinos Deltas, Lainie Friedman-Ross, PCW Hogendoorn, Jeantine Lunshof, Hülya Kayserili, Ulf Kristofferson,

28 Hansson MG, Dillner J, Bartram CR, Carlson JA, Helgesson G: Should donors be allowed to give broad consent to future biobank research? Lancet Oncol 2006; 7: 266-269.

29 Wendler D: One-time general consent for research on biological samples. $\mathrm{Br} \mathrm{Med} \mathrm{J}$ 2006; 332: 544-547.

30 Caulfield T, Kaye J: Broad consent in biobanking: reflections on seemingly insurmountable dillemas. Med Law Int 2009; 10: 85-100.

31 Hoedemaekers R, Gordijn B, Pijnenburg M: Solidarity and justice as guiding principles in genomic research. Bioethics 2007; 21: 342-350.

32 Chadwick R, Berg K: Solidarity and equity: new ethical frameworks for genetic databases. Nat Rev Genet 2001; 2: 318-321.

33 Helgesson G: Children, longitudinal studies, and informed consent. Med, Health Care Philos 2005; 8: 307

34 Greenbaum D, Sboner A, Mu XJ, Gerstein M: Genomics and privacy: implications of the new reality of closed data for the field. PLoS Comput Biol 2011; 7: e1002278.

35 Gurwitz D, Fortier I, Lunshof JE, Knoppers BM: Research ethics. Children and population biobanks. Science 2009; 325: 818-819.

36 Hansson MG: Ethics and biobanks. Br J Cancer 2008; 100: 8-12.

37 Hens K, Wright J, Dierickx K: Biobanks: oversight offers protection. Science 2009; 326: 798-799.

38 Brothers KB, Clayton EW: Biobanks: too long to wait for consent. Science 2009; 326: 798.

39 Kaufman D, Geller G, LeRoy L, Murphy J, Scott J, Hudson K: Ethical implications of including children in a large biobank for genetic-epidemiologic research: a qualitative study of public opinion. Am J Med Genet C Semin Med Genet 2008; 148C: $31-39$

40 Goodenough T, Williamson E, Kent J, Ashcroft R: Ethical protection in research: including children in the debate; in Smyth M, Williamson E (eds): Researchers and Their 'Subjects'. Bristol: The Policy Press, 2004; pp 55-72.

41 Bookman EB, Langehorne A, Eckfeldt J et al: Reporting genetic results in research studies: summary and recommendations of an NHLBI working group. Am J Med Genet 2006; 140: 1033-1040.

42 Cho MK: Understanding incidental findings in the context of genetics and genomics. J Law Med Ethics 2008; 36: 280-285, 212.

43 Clayton EW: Incidental findings in genetics research using archived DNA. J Law Med Ethics 2008; 36: 286-291, 212.

44 Ravitsky V, Wilfond BS: Disclosing individual genetic results to research participants. Am J Bioethics 2006; 6: 8-17.

45 Matsui K, Lie RK, Kita Y, Ueshima H: Ethics of future disclosure of individual risk information in a Genetic Cohort Study: a survey of donor preferences. J Epidemiol 2008; 18: 217-224.

46 Bredenoord AL, Kroes HY, Cuppen E, Parker M, Van Delden JJ: Disclosure of individual genetic data to research participants: the debate reconsidered. Trends Genet 2011; 27: 41-47.

47 Wolf SM, Lawrenz FP, Nelson CA et al: Managing incidental findings in human subjects research: analysis and recommendations. J Law Med Ethics 2008; 36: 219-248, 211.

48 Berg JS, Khoury MJ, Evans JP: Deploying whole genome sequencing in clinical practice and public health: meeting the challenge one bin at a time. Genet Med 2011; 13: 499-504.

49 Borry P, Evers-Kiebooms G, Cornel MC, Clarke A, Dierickx K: Genetic testing in asymptomatic minors Background considerations towards ESHG Recommendations. Eur J Hum Genet 2009; 17: 711-719.

50 Feinberg J: The child's right to an open future; in Aiken W, LaFollette $\mathrm{H}$ (eds): Whose Child? Children's Rights, Parental Authority and State Power. Totowa: Rowman and Littlefield, 1980; pp 124-153.

51 Ross LF: Screening for conditions that do not meet the Wilson and Jungner criteria: the case of Duchenne muscular dystrophy. Am J Med Genet A 2006; 140: 914-922.

(c)

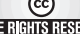

This work is licensed under the Creative Commons Attribution-NonCommercial-Share Alike 3.0 Unported License. To view a copy of this license, visit http://creativecommons. org/licenses/by-nc-sa/3.0/
Lidia Larizza, João Lavinha, Eric Legius, Béla Melegh, Teresa Pàmpols, Simone Possezzere, Jacinta Tan, Heloísa Santos, Joerg Schmidtke, Liesbeth Siderius, Heather Skirton, Sylvia Van der Pal and Tessa Van der Valk.

Members and observers of PPPC during the work on this document were: P Borry, A Cambon-Thomsen, MC Cornel (chair), F Fellmann, F Forzano, S Hodgson, H Howard, H Kayserili, C Patch, B Peterlin, W Rogowski, J Sequeiros, M Soller, A Tibben and L Tranebjaerg. 